\title{
Electronic Standardization and Design for Corporate Social Responsibility Information Disclosure*
}

\author{
HAO Qin \\ Quality Management Branch \\ China National Institute of Standardization \\ Beijing, China \\ haoqin@cnis.gov.cn
}

\begin{abstract}
According to national standards, this paper analyzes, with the help of XBRL, the electronic means of disclosing corporate social responsibility information and designs applicable conversion tools, which try to explore such a means of low cost and high efficiency. And this approach will facilitate the standardization and non-comparability of social responsibility information disclosure.
\end{abstract}

Keywords-Corporate Social Responsibility; Information Disclosure; XBRL; Electronic Standardization

Globally, non-monetary means is the way by which companies disclose the information about their social responsibilities. However, either its speed or efficiency fails to satisfy the needs of the general public. And it seems difficult to sort and collect relevant data. This paper hopes to offer ideas and solutions using Extensible Business Reporting Language (XBRL), which is a new means in this aspect.

\section{ANALYSIS ON ELECTRONIC TREND OF SOCIAL RESPONSIBILITY DISCLOSURE}

\section{A. Existing problems concerning social responsibility information disclosure}

In terms of disclosure approaches, enterprises disclose social responsibility information in electronic or written form, the latter of which includes special report and social responsibility report. Different disclosure methods lead to both non-standardization and non-comparability. Since no state mandatory requirement is explicitly specified like that for financial reports, many enterprises conduct the disclosure merely based on short-term factors such as corporate profile, national policies and social impact. So, some disclose their several years' information, which is neither normal nor continuous. As a result, the comparability and standardization of social responsibility information are affected in terms of time.

Different standards with varying criteria of categorizing the information and varying degrees of detailing are selected for the disclosure. So, enterprises should make their own choices. Guidance on Social Responsibility (ISO 26000), for

This Project was supported by the Presidential Foundation of China National Institute of Standardization titled Research and Empirical Analysis of Corporate Social Responsibility Management System (Project No.: 552014Y-3347). example, classifies social responsibility into seven topics, each of which falls into two levels; The Sustainability Reporting Guidelines issued by Global Reporting Initiative (GRI) divides it into economic, environmental and social aspects; also, some guidelines or courses on sustainable development reports give different categorizations, which vary greatly in quality, so that relevant reports become less standardized and comparable. What most enterprises disclose is lengthy texts, which contain no quantitative information and data measurement. Also, some description abounds in subjective embellishments. It is therefore difficult to compare them.

The disclosure of some information in this regard is now designed as being outputted as word, excel, pdf or html, All these are static formats. It is difficult to realize real-world exchange in electronic data.

\section{B. XBRL will be a prevailing electronic standard language}

XBRL based on XML, serves to define and exchange business and financial information. XBRL consists of Specification, Taxonomy and Instance Documents. Technically, XBRL represents application of XML in business reporting. Its electronic label can explicitly define particular information so that such information is available to application programs, thus simplifying and streamlining manual procedures. It reduces the costs of corporate information disclosure and improves information correlation and policy-making efficiency. So in recent years, XBRL has been made international rapidly for widespread application in financial reports and relevant supervision reports[1]. Voluntary or compulsory application in financial and other reports are stated in the USA, UK, Australia, Canada and France. In China, it has been explicitly required by Shanghai Stock Exchange and Shenzhen Stock Exchange that XBRL technology that listed enterprises should apply XBRL technology in information disclosure. All these show us, a new era of information electronization, spearheaded by XBRL technology, will come soon[2].

\section{XBRL-based Electronic standardization of social responsibility information}

Most of the social responsibility information is not financial information that cannot be quantified. XBRL is 
designed for financial reports, most of which contain quantitative information. In particular as increasing nonquantitative information is incorporated in financial reports over the globe, financial reports contain a growing quantity of such information. It is reflected and regulated in XBRL. Nonquantitative elements in financial information demonstrates that the non-quantitative non-financial information may also be described by XBRL technology. Especially, either voluntary or compulsory application of XBRL technology many countries denotes that XBRL technology suffices to be applied to both financial and non-financial reports. The Guidance on Social Responsibility (Version G4) under the consideration of GRI attempted to introduce XBRL; AECA formulated the standards for classification of corporate social responsibility, passed the international certification at the level of "Acknowledged" by XBRL International and provided technical support for preparing, delivering and handling the reports of companies and other entities about corporate social responsibility activities and status. Shanghai Stock Exchange is also discussing its application in this field. All these facts tell us XBRL has entered the area of social responsibility. Thus, it may be used for such disclosure to facilitate standardization and comparability of the information disclosure in China.

\section{SPECIFICATION FOR ELECTRONIC INFORMATION DISCLOSURE OF CORPORATE SOCIAL RESPONSIBILITY INFORMATION}

\section{A. Format of electronic documents for corporate social responsibility information}

1) Structure: An electronic document consists of head and body. The head contains document title and corporate name; the body represents the main information disclosure and includes the corporate social responsibility information shown as below.

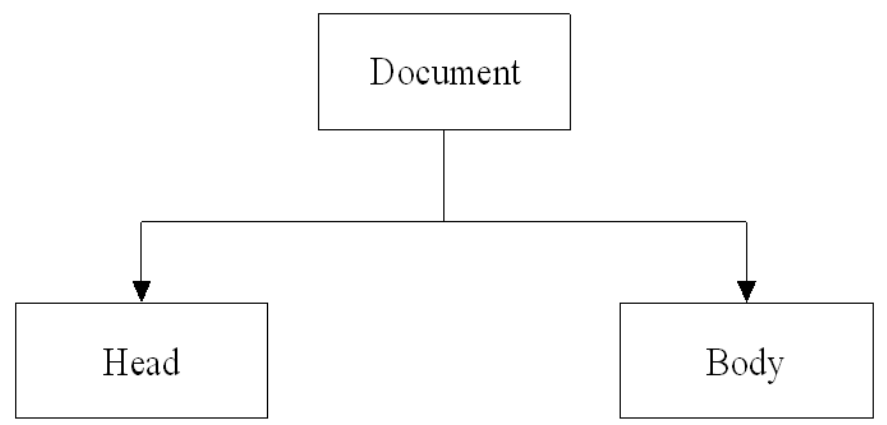

Fig. 1. Document Structure

2) Organization model: The content of a document is composed of necessary data element information organized in accordance with the requirements of document rules.

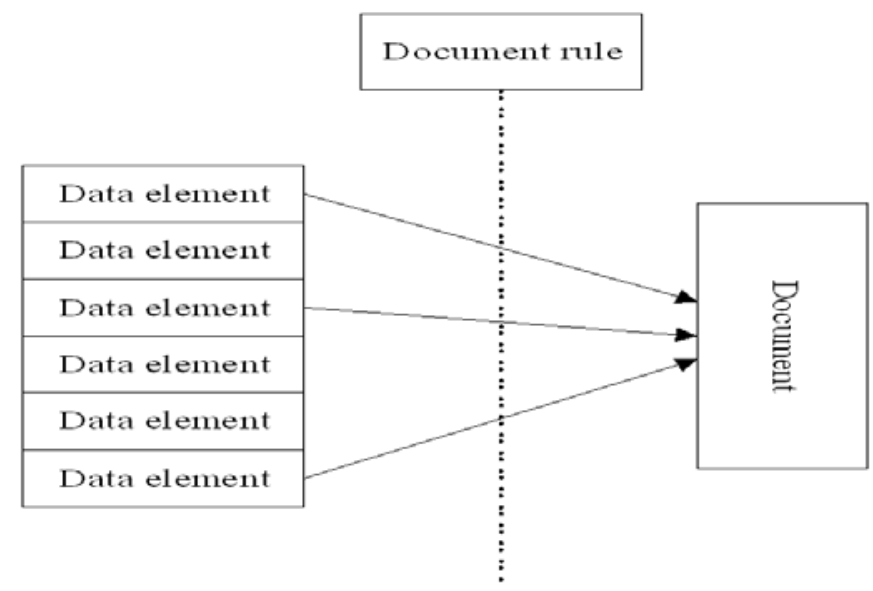

Fig. 2. Document Organization

3) Generation of electronic documents:Particular electronic descriptions serve to describe disclosure information and rules and generate electronic documents, which are structural documents in digitalized form.

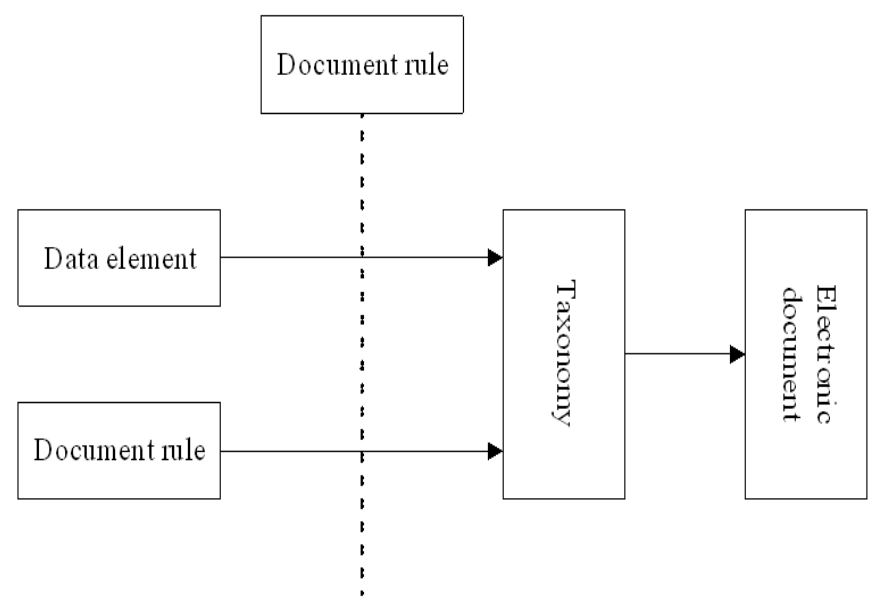

Fig. 3. Generation Process of Electronic Document

\section{B. Classification criteria for electronic information disclosure of corporate social responsibility information}

This study prepares the classification criteria for electronic disclosure of corporate social responsibility information on the basis of the national standard Guidance on Social Responsibility (GB/T 36000-2015) issued in June 2015.

1) Principles: The principles of importance, operability and uniqueness are observed in the selection of classification criteria indicators. Importance means the importance of responsibility of analyzing key themes for national standards of social responsibility and relevant topics, which is selected according to the degree of importance. Operability indicates that indicators should be measurable, available, reliable, complete and identical. Uniqueness denotes all duplicate or similar indicators should be integrated.

2) Classification: Corporate social responsibility information disclosure falls into 2 categories, each of which is divided into 
10 sub-categories. The basic information describes corporate profile like fundamental, structure and technical information. However, the information about social responsibility includes corporate governance, human rights, labor practice, environment, fair operation, consumer, social engagement and development.

\section{Generation of electronic documents in this regard}

The information of corporate electronic documents is divided into a series of data items according to classification standards and the technical specification for electronic application of information disclosure is used. Also, these data are organized in particular formats and then become instance documents.

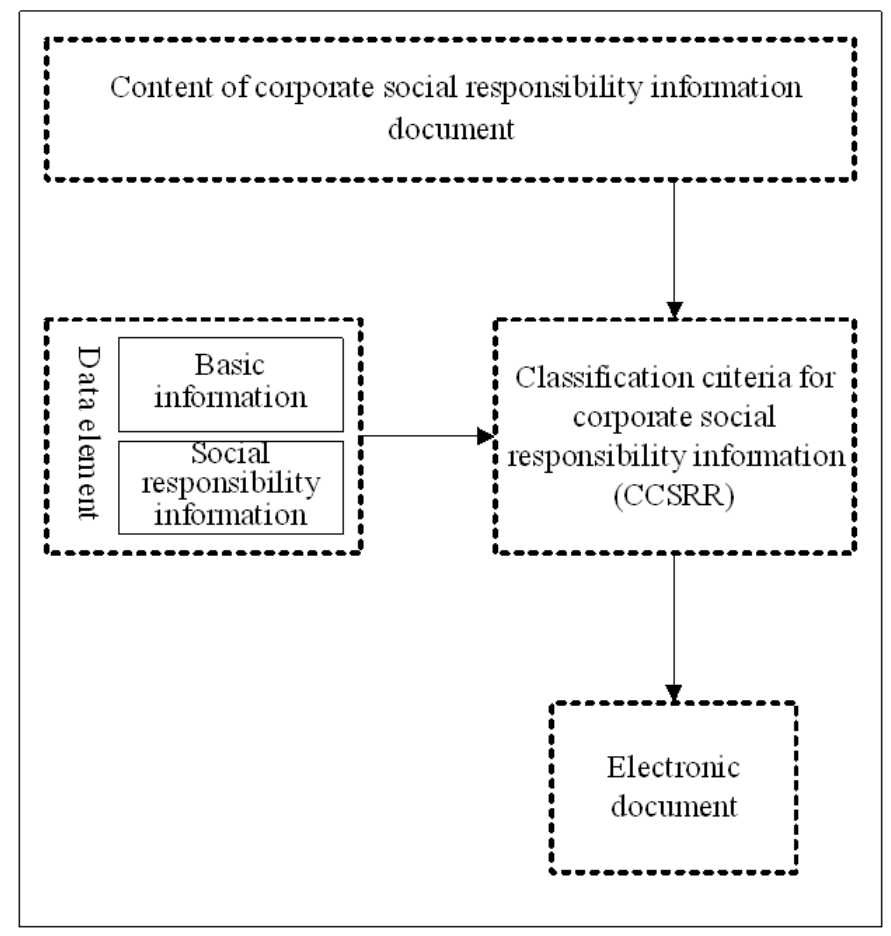

Fig. 4. Instance Document

\section{DESIGN OF ELECTRONIC TOOLS FOR CORPORATE SOCIAL RESPONSIBILITY INFORMATION DISCLOSURE}

Promoting electronic specification of corporate social responsibility information allows enterprises to apply it in reports and finally regulates corporate social responsibility information disclosure. It thus becomes necessary to develop a set of conversion tools that are easy to use and powerful.

\section{A. Functional demand}

There are mainly four types of conversion tools: user management, system management, data management and statistical analysis. The overall functional block diagram is shown as below. Conversion tools enable the disclosure of corporate social responsibility information according to electronic specification and help enterprises to enter, edit, browse, report, import and export data on the electronic interface. According to basis, corporate social responsibility information is disclosed on an annual basis and relevant information is allocated to generate analytical statements on time and industry dimensions in the system.

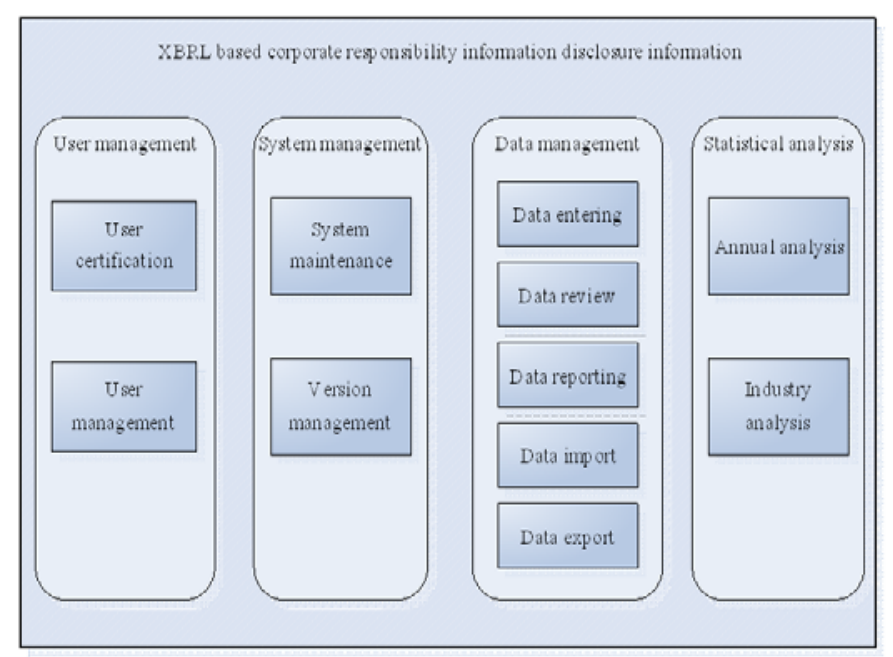

Fig. 5. Functional Chart of Conversion Tools

\section{B. Overall Design}

The tool system has three layers: interface display, business logistics and database operation. The interface display layer interacts with users, receives user input and interface operation and transmits information package into business logistics layer. The display layer includes data display, version display, user display and log display.

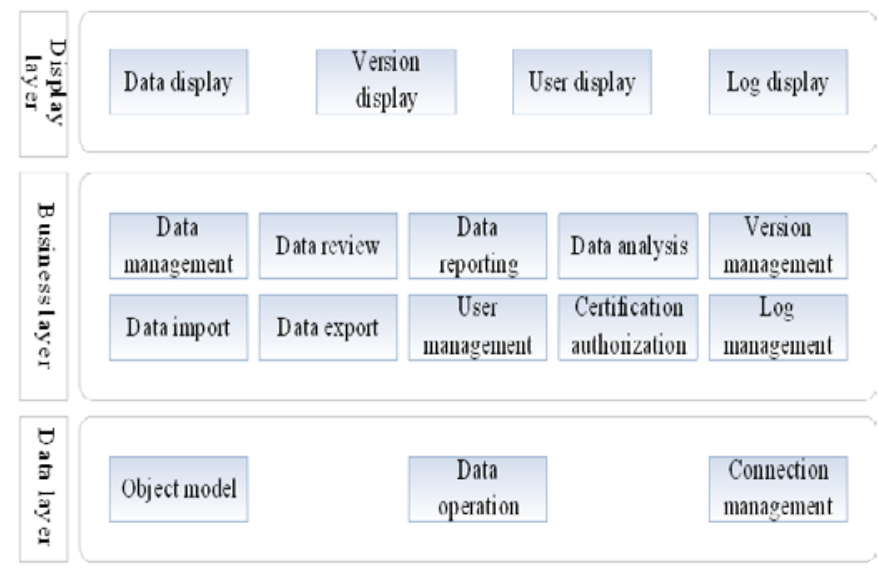

Fig. 6. Structural Chart of Tool System

\section{REFERENCES}

[1] Han Yue, “Current Status of XBRL Application,”J. Finance and Economics, 9rd ed., 2011.

[2] Zhu Jianguo, "Comparative Analysis of XBRL Application in Shanghai Stock Exchange and Shenzhen Stock Exchange,”C. Collection of Papers for the 8th National Annual Conference of Accounting Information Technology of Accounting Society of China (Part II), 2009, pp. 628-634. 